\title{
A POLÍTICA CRIMINAL AMERICANA E SEU PAPEL NA CRIAÇÃO DAS CORTES DE DROGAS: INFLUÊNCIAS HISTÓRICAS SOFRIDAS PELO PROGRAMA DE JUSTIÇA TERAPÊUTICA
}

Daniel Pulcherio Fensterseifer ${ }^{1}$

FENSTERSEIFER, D. P. A política criminal americana e seu papel na criação das cortes de drogas: influências históricas sofridas pelo programa de justiça terapêutica. Rev. Ciênc. Juríd. Soc. UNIPAR. Umuarama. v. 17, n. 1, p. 27-42, jan./jun. 2014.

RESUMO: O presente estudo discute a criação do Programa de Justiça Terapêutica no Brasil a partir de um enfoque histórico, partindo-se da política criminal de drogas americana e seu desenvolvimento ao longo das décadas, bem como sua influência sobre as políticas brasileiras. Trata-se de uma pesquisa bibliográfica para a qual foram eleitos dois autores americanos como referência principal acerca da política criminal americana sobre drogas, bem como outras obras relacionadas ao tema que contribuíssem na discussão do tema proposto por David Garland e Jonathan Simon e que pudessem explicar o paralelismo com o contexto brasileiro ao passar do tempo. Pode-se afirmar que a política criminal brasileira sobre drogas sofreu, e continua sofrendo, grande influência das políticas americanas. Vislumbra-se que inúmeras medidas tomadas nos Estados Unidos foram reproduzidas fielmente no Brasil, com alguns anos de atraso, causando consequências semelhantes, especialmente aquelas que se mostram confirmadoras de um sistema criminal seletivo e de reforço da exclusão social. Recentemente, entretanto, surge uma ideia que aparenta destoar dessas políticas negativas e busca minimizar os efeitos da aplicação do direito penal enquanto reforça o tratamento do que é apontado como principal fator de uma gama de comportamentos criminosos, qual seja, o uso de drogas. Com o afastamento do sujeito das consequências penais, aproximando-o de um tratamento, as Cortes de Drogas buscam reduzir a criminalidade que até então não vinha sendo combatida de forma adequada, considerando as finalidades propostas pelas políticas criminais adotadas ao longo do tempo.

PALAVRAS-CHAVE: Política criminal de drogas; Cortes de drogas; Crimes; Drogas.

DOI: https://doi.org/10.25110/rcjs.v17i1.2014.5353

${ }^{1}$ Doutorando em Ciências Criminais pela PUCRS. Professor de Direito Penal e Processo Penal na Universidade Regional Integrada do Alto Uruguai e das Missões - URI/FW. Bolsista Capes. Advogado Criminalista. E-mail: danielpulcherio@uri.edu.br 


\section{INTRODUÇÃO}

No final da década de 80, especificamente na cidade de Miami, foi criada a primeira Corte de Drogas americana, a primeira experiência desse tipo em todo o mundo. Tal mecanismo surgiu como resultado de um diagnóstico referente à delinquência associada à droga e a política criminal existente àquela época. O discurso de que "nada funciona" e a insuportabilidade dos índices carcerários constituíram o combustível para que um grupo de profissionais do direito buscasse alguma alternativa ao modelo tradicional de operacionalização da justiça, tendo em vista que a pena de prisão não cumpriu nenhum dos objetivos a que se propôs, servindo unicamente como um instrumento de exclusão do sujeito perigoso da sociedade, mediante a sua incapacitação.

Ademais, a prisão em nenhum momento possibilitou que os dependentes químicos pudessem tratar ou refletir minimamente sobre essa sua condição, remanescendo, após a liberdade, esse importante fator desviante que, por si só ${ }^{2}$, tem o poder de conduzir o cidadão à prisão, fomentando, com isso, a superlotação carcerária.

Nessa conjuntura, observou-se que o perfil da população carcerária estava um tanto alterada, caracterizada por ser uma massa de infratores relacionados a crimes cometidos em razão do consumo de drogas, ou em outras palavras, pessoas que cometeram crimes por estarem drogados no momento do delito praticado ou porque haviam cometido o crime para poder sustentar o próprio vício. Diante dessa constatação, no ano de 1989 iniciaram-se os trabalhos da primeira DrugCourt.

Este marco histórico não surgiu abruptamente, ele foi sendo construído ao longo das décadas do século XX, a partir da evolução da política criminal americana desde um Estado de bem-estar social a uma guerra contra as drogas. Política essa que é reproduzida por muitos países ao redor do globo.

Da mesma forma, as Cortes de Drogas também se espalharam no mundo desde sua criação, surgindo como uma tentativa de abordar de forma diferente os delitos relacionados ao consumo de drogas frente à derrota do Estado nessa "guerra contra as drogas".

O presente estudo pretende percorrer essa trajetória a fim de demarcar o contexto histórico que aparece por trás das Cortes de Drogas americanas e que tentam encontrar seu espaço, embora sob uma forma adaptada, no sistema de justiça brasileiro.

${ }^{2} \mathrm{O}$ presente paper pretende abordar unicamente o contexto histórico no qual surgiu as Cortes de Drogas, não tendo por objetivo discutir a (des)criminalização do uso de drogas. Nos Estados Unidos, pessoas que são flagradas portando entorpecentes podem ser detidas pela polícia e receberem pena de prisão. No Brasil, após a nova lei de drogas, n. 11.343/08, não há mais previsão legal de pena privativa de liberdade para quem é condenado por portar ou possuir droga para consumo próprio (art. 28).

Rev. Ciênc. Juríd. Soc. UNIPAR, v. 17, n. 1, p. 27-42, jan./jun. 2014 


\section{A EVOLUÇÃO DA POLÍTICA CRIMINAL AMERICANA}

A história da política criminal americana inicia juntamente com a chegada dos imigrantes europeus ao novo continente, tendo a commom law desembarcado de navio na companhia dos primeiros colonos que chegaram ao território que hoje corresponde aos Estados Unidos. Tal circunstância forjou a estrutura jurídica norteamericana, sem deixar de considerar em seu desenvolvimento toda a diversidade cultural dos imigrantes que se estabeleciam no "Novo Mundo". (HERINGER JÚNIOR, 2013, p. 32).

Desde cedo, era cristalina a diferenciação entre delitos de natureza leve e grave-fellonies e misdemeanors - sendo eles processados diversamente. Procedimentos simplificados e de competência municipal eram operados para os crimes leves, enquanto que os procedimentos mais complexos, de responsabilidade estadual, eram destinados para aqueles delitos considerados graves. Cumpre destacar que até a década de 20 a esfera federal não possuía atribuições relativas ao controle da criminalidade, vindo a buscar espaço na rede de controle do crime mais tarde, sobremaneira no combate ao narcotráfico (HERINGER JÚNIOR, 2013, p. 33).

O combate à delinquência era atribuição da polícia, que teve seu surgimento de forma profissionalizada entre 1840 e 1920 e que era contaminada pela corrupção decorrente da indicação de Xerifes que, para manterem seus postos e autoridade, realizavam verdadeira militância em favor dos políticos que os empossavam. De 1920 a 1970 a polícia sofreu um processo de transformação, afastando-se das influências políticas corruptas e aproximando-se do modelo que existe hoje em dia. (HERINGER JÚNIOR,2013, p. 36).

Ainda no século XIX, mais precisamente no ano de 1898, houve o fato que para Flávio A. Fontes de Lima foi o marco histórico do início ao combate às drogas liderado pelos Estados Unidos. Isso porque, em tal ano, no curso da guerra entre os Estados Unidos e a Espanha, em razão da invasão das Filipinas, as elites puritanas pressionaram o governo americano para que fosse tomada alguma atitude contra os consumidores de ópio, uma vez que eles, juntamente com as prostitutas, estavam colocando em risco a saúde dos marinheiros americanos (LIMA, 2011. p. 66).

Ao longo de todo o século XX o combate às drogas foi se intensificando cada vez mais, até o momento em que foi declarada a "War on Drugs" (guerra às drogas), pelo então presidente Nixon, na década de 70 .

Concomitantemente a esses processos constrói-se o welferismo penal. Em meados da década de 1890 surge o estado de bem-estar penal, sendo desenvolvido ao longo dos anos e atingindo seu ápice nas décadas de 50 e 60 nos Estados Unidos. Até a década de 70 tratava-se de um marco consolidado das 
políticas públicas trabalhadas nesses países, reconhecendo que as intervenções de caráter penal deviam ser instrumentos de reabilitação e não de meros castigos retributivos. Essa reabilitação buscava corrigir o sujeito desviante, tendo como característica a individualização da resposta penal, medida de acordo com o nível de obediência do apenado e do risco que ele representava (GARLAND, 2005. p. 81-83), podendo ser dito que, de certa forma, se caracteriza, conforme o pensamento foucaultiano, como um processo de domesticação do sujeito perigoso (FOUCAULT, 1991).

Em razão do "boom" econômico ocorrido nas décadas de 50 e 60 , o governo pôde trabalhar no sentido de diminuir as desigualdades existentes na sociedade, sobretudo pelo aumento das redes de prestações sociais, podendo, agora, colaborar com as famílias que foram deixadas de lado pela prosperidade e pelo progresso social. Dessa forma, o governo ainda pôde focar suas ações naqueles que não se enquadravam como "merecedores de ajuda", um grupo formado basicamente por pobres, delinquentes juvenis e os sujeitos que estavam presos (GARLAND, 2005, p. 101-102).

Diante disso, novas leis foram promulgadas, leis que determinavam alvos das políticas criminais, elegendo populações específicas que deveriam ser controladas pelo Estado como forma de reduzir a criminalidade. Embora essa manobra fosse extremamente estigmatizante, recebeu apoio inclusive de outras minorias, as quais também acabavam sendo rotuladas por novas leis instituídas para o fim de protegê-las, como ocorreu, por exemplo em relação às mulheres. Isso fez com que esses mesmos grupos apoiassem essa nova onda legislativa que, assim como elegiam alvos de defesa, deveriam eleger alvos a serem combatidos. Foram as chamadas políticas afirmativas possibilitaram esse efeito reverso.(SIMON, 2009. p. 79).

A criação de leis direcionadas a certas populações acabava muitas vezes por "legitimar" as estratégias governamentais. A promulgação de leis direcionadas a rotular negros e jovens como alvos acabavam "caindo como uma luva" em uma época em que haviam muitas manifestações populares contra a guerra do Vietnã. Essas manifestações eram encabeçadas por lideranças juvenis e por movimentos negros, as principais vítimas da guerra e que agora estavam colocando em risco a ordem social por meio das manifestações populares. A solução foi criminalizar esse tipo de manifestação e o resultado foi que os alvos das políticas invariavelmente fossem os perpetradores daqueles delitos.

No welfare penal o tratamento advinha de um diagnóstico e as sanções penais sempre eram acompanhadas de um assessoramento técnico de profissionais que tinham o poder de realizar diversas intervenções sem a obrigação de prestar justificativas, facilitando a arbitrariedade de muitas medidas impostas aos condenados(GARLAND, 2005. p. 84). A tendência ao aprimoramento dessas 
técnicas se torna mais saliente no momento em que o próprio modelo de welfarestate começa a colapsar (GHIRINGHELI, 2006. p. 50).

Entre a década de 1890 até a de 1960-momento em que houve um significativo aumento nas taxas de criminalidade e de violência-ainda acreditava-se que a justiça penal era um mecanismo suficiente e adequado para fazer com que essas taxas pudessem retroceder aos níveis que a industrialização havia trazido consigo. No início do século 20 , a justiça penal estava bem confiante em relação a sua eficiência no combate ao crime. As taxas de criminalidade, embora aumentadas, ainda não haviam atingido índices alarmantes e havia uma confiança generalizada nas instituições estatais de controle do delito, embora Garland aponte que essa funcionalidade não era totalmente verdadeira, sendo o mais provável que as conquistas em matéria de controle do delito se deram mais por meios informais do que pelo próprio Estado (GARLAND, 2005. p. 80).

Para Rodrigo Ghiringhelli de Azevedo, naquele momento, houve um grande investimento em mecanismos de controle social que visavam à manutenção da ordem, sendo "o ideal de ressocialização incorporado como objetivo central dos mecanismos de controle punitivo" (GHIRINGHELI, 2006. p. 44). Entretanto, segue o autor afirmando que todos esses elementos começaram a ser questionados no período pós-guerra, período esse chamado de capitalismo desorganizado ou modernidade tardia, quando "a sociedade industrial dá origem à sociedade do consumo de massa" (GHIRINGHELI, 2006. p. 45).

\section{DENTRE OS ELEMENTOS DA DESCENTRALIZAÇÃO DO PODER, O PAPEL DOS PROMOTORES}

No final da década de 70 e na década de 80 foi vivido o declínio do ideal da reabilitação, frase essa que deu nome ao livro de Francis Allen, datado de 1981, que popularizou esse sentimento de frustração em relação aos objetivos do correcionalismo (GARLAND, 2005. p. 41).

Os tratamentos para reintegrar o apenado à comunidade foram sendo abandonados. A influência da escola positivista e seus métodos científicos perderam força, sobretudo na década de 70 , em meio a uma explosão de diversidade cultural e luta pelo reconhecimento de direitos civis, sendo reconhecido que o fracasso em relação ao controle da criminalidade ocorreu em razão da desorganização da sociedade (HERINGER JÚNIOR, 2013. p. 56).

Até a chegada desse momento, muitas coisas ocorreram nos Estados Unidos que modificaram a estrutura de combate à criminalidade. $\mathrm{O}$ papel dos Promotores de Justiça foi uma dessas modificações que se destacaram, os quais assumiram uma postura muito mais preocupada com a aparência de bem-estar social do que com a eventual ausência de democracia nos procedimentos 
judiciais(SIMON, 2009. p. 33).

Fracassos governamentais com significados muito simbólicos, como o assassinato do presidente Kennedy e a derrota na guerra do Vietnã, eram, juntamente com a criminalidade das ruas (street crimes), veiculados diariamente pelos meios de comunicação em massa. Dessa forma, com a ideia de que o Estado não tinha mais condições de ser o ente superprotetor da comunidade, o papel do Promotor de Justiça ganha especial relevo, sendo ele visto agora como o "novo líder do New Deal". Ademais, ao assumir tal posição, verifica-se um deslocamento do poder de punir, não mais centralizado na figura do Estado, mas também nas mãos desses Promotores que vinham ganhando discricionariedade, inclusive para determinar quais crimes deveriam ser processados, se a pena aplicada deveria ser curta ou de longa duração e qual a destinação que o condenado deveria seguir (SIMON, 2009. p. 34-35).

A estrutura que sustentava essa promotoria era composta de promotores que eram eleitos em seus estados e que dispunham de uma equipe que o ajudava na tarefa de dar andamento aos processos (HERINGER JÚNIOR, 2013. p. 56).

Com a consolidação do pleabargaining os processos foram gradativamente transferidos do júri - onde eram geralmente morosos - para um procedimento muito mais ágil, no qual o réu assumia a culpa para evitar ser processado perante o júri e em troca recebia uma pena mais branda ou até mesmo uma suspensão condicional dela.

Sobre essa sumariedade nos processos criminais, Heringer afirma que:

O procedimento de negociação da culpa instalou-se duradouramente porque beneficia, de um modo ou de outro, todos os envolvidos. O acusado alcança a solução de seu caso mais rapidamente e tem sua situação penal atenuada, além de não se sujeitar à incerteza de um julgamento pelo júri. O promotor economiza recursos pessoais e materiais do governo, os quais podem ser canalizados para outros casos mais importantes. O advogado dativo recebe sua remuneração logo, podendo dedicar-se a outros clientes. O defensor público tem aliviada a sua sobrecarga de serviço. E o juiz livra-se de um julgamento demorado, bem como tem seu trabalho reduzido, pois como regra acaba aceitando a proposta de apenamento sugerida pelo acusador (HERINGER JÚNIOR, 2013. p. 47).

Nesse contexto, os Promotores assumiram um papel de representantes do povo e não estavam subordinados ao prefeito ou ao governador, adquirindo poderes de escolha sobre a possibilidade de acusar ou não o sujeito, de acordo com os crimes que eram tidos como alvos de combate (SIMON, 2009. p. 38-43). 


\section{A SUPERPREOCUPAÇÃO COM A VÍTIMA}

Ainda no final da década de 70 e na década de 80, as críticas ao correcionalismo se intensificaram, sobretudo em relação às condenações indeterminadas e aos tratamentos individualizados que eram empregados em relação aos presos. Aliás, a prisão era vista por esses críticos como um mecanismo de repressão contra negros, jovens, pobres e outras minorias, ou seja, tratava-se de um instrumento de criação de desigualdade. Em razão disso também, entendiam que o encarceramento deveria ser mais igualitário e com penas com duração determinada (GARLAND, 2005. p. 107-109).

Nesse período a criminalidade continuava a aumentar, fazendo com que agentes de combate ao crime chegassem a conclusão de que "nada funciona". A polícia não se mostrava efetiva como se acreditava ser e as pesquisas criminológicas desenvolvidas até então não haviam obtido sucesso, ou seja, aparentemente não havia mais nada que pudesse ser feito por parte do Estado para que os índices de criminalidade pudessem retornar a um patamar mais baixo (GARLAND, 2005. p. 120).

Nesse contexto, a vítima ganha especial relevo nessa política criminal. Ela se torna o centro das atenções. Aliás, destaca-se que esse relevo não pertencia apenas às pessoas que haviam sido vitimadas, mas pertencia também àquelas que se apresentavam como vítimas em potencial. Nessa conjuntura, a vítima possuía um perfil, ou seja, a população a ser protegida dessa criminalidade generalizada era essencialmente branca e que morava em zonas de subúrbios e de classe média (SIMON, 2009. p. 38-43).

A ideia de que todos nós somos vítimas em potencial espalhou um desconforto entre a comunidade, um sentimento de insegurança que muitas vezes não correspondia com a realidade. Políticas de prevenção aos delitos violentos eram tomadas mesmo que a realidade mostrasse que esse tipo de delito não representava a criminalidade da região. O Estado, adotando uma postura de que a prevenção à criminalidade vai além do próprio Estado, embutiu na comunidade parcela dessa responsabilidade, mediante o estímulo de programas como a "Neighborhood Watch", o incentivo ao uso de trancas em automóveis, a substituição do uso de dinheiro por cartões, dentre outras condutas que buscavam reduzir as oportunidades de ação dos delinquentes, os quais poderiam ser qualquer um e estar em qualquer lugar.

O governo mudou também os seus critérios de avaliação dos sucessos e fracassos de sua atuação. Passou-se a considerar, por exemplo, o número de chamadas atendidas pela polícia - especialmente após a criação de recursos como o 911, que representava a capacidade da polícia estar em qualquer lugar em um espaço de tempo muito reduzido para proteger a vítima -, bem como a quantida- 
de de pessoas que eram condenadas e presas em relação a quantidade de crimes que havia (GARLAND, 2005. p. 203).

O governo começou a trabalhar mais em relação às consequências do crime do que sobre as suas causas. A assistência às vítimas se tornou a grande missão do Estado, reconhecendo-se direitos a elas e garantindo-lhes participação no processo penal. A comunidade toda deveria ajudar o Estado a combater o crime, uma vez que essa missão estava além das capacidades governamentais e demandava a colaboração de todos (GARLAND, 2005. p. 203).

\section{O INCREMENTO DA PUNITIVIDADE POPULISTA}

Já cansados com o sentimento de insegurança e com o aumento das taxas da criminalidade os cidadãos começaram a exigir que o governo tomasse medidas mais severas de combate à delinquência, dando-se início a uma política muito mais retribucionista. Para atender aos anseios da comunidade, o governo iniciou um trabalho que buscasse atender a esses pedidos, realizando diversas ações de fácil percepção pública, mesmo quando elas não correspondiam a técnicas realmente efetivas ao que se propunham. Essas ações se tratavam,na maioria das vezes, deiniciativasde cunho meramente populista.A ideia era transmitir a mensagem de que todo o esforço necessário por parte do Estado estava sendo realizado, mesmo quando as medidas adotadas contrariavam os achados científicos sobre meios de reduzir o crime.

Dentre esses grupos que reivindicavam o endurecimento penal por parte do Estado, encontravam-se até mesmo aqueles que antes vinham solicitar a implementação de direitos sociais, movimentos esses ligados a mulheres, homossexuais e outras minorias (HERINGER JÚNIOR, 2013. p. 76).

\section{A MUDANÇA DO PENSAMENTO CRIMINOLÓGICO E O SURGIMEN- TO DA "GUERRA CONTRA AS DROGAS"}

O pensamento criminológico também sofreu mudanças. A ótica principal passou a ser a falta de oportunidades como fator de grande importância para o cometimento de delitos. Diante disso, o correcionalismo se modifica, ganhando contornos de um tratamento muito mais individualizado, fomentando a educação e o desenvolvimento de técnicas laborativas para que o preso possa ser absorvido pelo mercado de trabalho quando terminar de cumprir sua pena. Trata-se, de um certo modo, de uma tentativa de retornar ao antigo ideal de bem-estar social, tendo em vista que o crime passou a ser encarado como um elemento intrínseco à sociedade, o qual não demanda, para sua perpetração, qualquer motivação de ordem especial ou anomalia - tais como doenças e transtornos biopsicológicos. 
Entendia-se que políticas de bem estar seriam capazes de retificar o indivíduo desviante (GARLAND, 2005. p. 52-53).

Firmou-se a convicção de que os delinquentes poderiam sim ser reformados pelas agências governamentais. $\mathrm{O}$ simples castigo foi considerado irracional e contraproducente e o tratamento dispendido aos condenados exigia mais conhecimento técnico e medidas corretivas mais individualizadas. Nesse cenário, o castigo veio a ser substituído por tratamento, uma vez que o entendimento que imperava era de que a imposição de sofrimento ao condenado, a indignação pública e a vingança das vítimas tratavam-se de fins em si mesmos (GARLAND, 2005. p. 90).

Em que pese todas as modificações que a política criminal vinha sofrendo continuamente, uma sensação permanente de crise continuava a pairar ao longo da década de 90, sobretudo diante do contínuo aumento da criminalidade e das volumosas taxas de reincidência, as quais demonstravam empiricamente o fracasso das teorias adotadas até então (GARLAND, 2005. p. 60).

Esse aumento da criminalidade veio diretamente ligado aos delitos relacionados às drogas, sobretudo nas décadas de 70 e 80 (GARLAND, 2005. p. 159).

A desigualdade entre as classes sociais despontou ao longo dos anos 80 e 90, período que coincidiu com a dominação de uma nova direita sobre o cenário político.

Nos mandatos de Nixon e Mitchell, houve um forte investimento econômico na guerra contra o crime, adotando-se uma política que visava a atender aquilo que a população desejava, de uma forma populista, coincidindo, contudo, com os maiores escândalos de corrupção vivenciados nos Estados Unidos (SIMON, 2009. p. 54). Aliás, foi justamente o presidente Richard Nixon que, em 1973, tornou conhecida a expressão "War on Drugs" (guerra às drogas), encaminhando para o congresso americano a mensagem de que as drogas representavam um grande perigo para toda a nação americana e que deveria ser dado um enfoque à repressão interna e externa, enfatizando-se, também, o tratamento compulsório para os drogados (LIMA, 2011. p. 63).

Ainda na década de 70, mais precisamente no ano de 1974, foi criada a DEA - Drugs Enforcemente Agency, órgão este que foi o responsável pela implantação de diversas políticas proibicionistas em relação às drogas tanto dentro, quanto fora dos Estados Unidos (LIMA, 2011. p. 64).

Jimmy Carter, eleito presidente dos Estados Unidos no ano de 1976, sinalizou num sentido de que as penas para os usuários de drogas deveriam ser reduzidas, alegando que os danos causados pela punição não poderiam ser mais danosos do que as consequências do próprio consumo da droga. Contudo, imediatamente foi acusado de ser excessivamente liberal e se viu obrigado a abando- 
nar seu posicionamento, sobretudo após o fato de um dos seus assessores ter sido flagrado possuindo cocaína (LIMA, 2011. p. 64).

\section{A OBSESSIVIDADE PELA DISCIPLINA E OS NOVOS RECURSOS TECNOLÓGICOS}

Na década de 80, as importantes mudanças que ocorreram na liberdade econômica e em relação ao controle social foram o cenário do aumento da criminalidade dos delitos violentos relacionados às drogas, aumentando também a sensação de insegurança da população. O delito passou a ser visto com falta de disciplina e de autocontrole, justificando o surgimento de políticas como a "zero tolerance" e a lei dos "3strikes e está fora" (GARLAND, 2005. p. 177).

Em 1988 houve a edição do novo Anti-Abuse Drug Act o qual previa o reestabelecimento das penas de morte para traficantes de drogas, preconizando uma América livre das drogas (LIMA, 2011. p. 64).

Nessa mesma década de 80 houve uma comercialização da justiça, ou seja, as agências de governo estavam investindo dinheiro privado em diversas questões que envolviam o combate ao crime. Ademais, análises de gestão foram incorporadas como indicadores de performance dessas agências.

$\mathrm{Na}$ década de 90 foi a vez da incorporação de computadores que deram um ar tecnológico ao controle do delito, usados pelas autoridades policiais e penitenciárias, concomitantemente a dados georreferenciaidos que apontavam qual as medidas que deveriam ser adotadas (GARLAND, 2005. p. 198).

Ao longo da década de 90 houve um aumento significativo dos programas de tratamento aos delinquentes na comunidade e nas prisões. Os sujeitos ainda eram avaliados e classificados. Eram buscados e identificados os fatores de riscos e as possibilidades de tratamento. As avaliações psicossociais de diagnósticos e cura estavam em voga (GARLAND, 2005. p. 279).

\section{ALGUNS RESULTADOS DESSA TRAJETÓRIA}

Garland aponta que essa nova cultura do controle veio formada sobre três pontos principais, quais sejam, um welferismo penal modificado; uma criminologia do controle; e uma forma econômica de racionamento (GARLAND, 2005. p. 287). O tratamento era a política da vez, mas tal tratamento só era justificado quando seu resultado indicasse a queda dos fatores de risco para a sociedade, ou seja, o tratamento era disponibilizado apenas para aquela população de delinquentes que poderia de alguma forma aproveitar esse tratamento e não reincidir (GARLAND, 2005. p. 288).

Alternativas ao cárcere eram utilizadas, especialmente, a probation. 
Contudo, sua aplicação vinha embebida em punitividade, sempre associada ao uso de pulseiras eletrônicas, testagens de uso de drogas e outros mecanismos de controle.

Atualmente, o Estados Unidos é o país que possui mais pessoas presas no mundo, cerca de $25 \%$ de toda a população carcerária, mesmo contando com 5\% da população mundial. Nas décadas de 80 e 90 houve um incrível aumento de pessoas presas, sendo que no ano de 2010 eles atingiram a marca de 2.266.800 presos, 4.055 .515 condenados em probation e 840.676 submetidos à parole, chegando-se à incrível marca de 7.076.200 pessoas sob o controle direto do Estado. Destaca-se dentro desse universo que $47 \%$ dos presos estaduais e $93 \%$ dos presos federais respondiam por crimes não violentos (HERINGER JÚNIOR, 2013. p. 83-85).

Especificamente, em relação aos crimes associados às drogas, Heringer aponta que:

Coube principalmente à famigerada warondrugs promover o confinamento da população marginalizada, já que o objetivo inconfessável do combate ao uso e ao tráfico de drogas parece ser o de segregar a nova underclass gerada pelo desmantelamento do Estado de bem-estar social, como revelam as estatísticas prisionais. De fato, em meados da década de 1990, os usuários e os traficantes de entorpecentes totalizavam cerca de $60 \%$ da população carcerária federal e $20 \%$ da estadual, percentuais que se mantiveram até o final da década de 2000 , apesar de terem apresentado uma pequena redução. E, seguindo essa orientação repressiva, também o número anual de detenções relacionadas a drogas tem apresentado um crescimento progressivo: $581.000 \mathrm{em} \mathrm{1980,811.000} \mathrm{em} \mathrm{1985,1.090.000} \mathrm{em} \mathrm{1990,} 1.450 .000$ em 1994, 1.506.000 em 1996 e 1.745 .000 em 2004 (HERINGER JÚNIOR, 2013. p. 85).

É justamente nesse cenário que o movimento a favor das Cortes de Drogas se afirma, buscando oferecer tratamento aos dependentes químicos para que, "curados", não voltem a delinquir. É importante destacar, ainda, que para o sujeito poder ingressar no programa de tratamento das Cortes de Drogas deve assumir culpa pelo delito que está sendo acusado, ou seja, o tratamento é uma medida associada à parole.

\section{DO PROIBICIONISMO LEGISLATIVO BRASILEIRO AO PROGRAMA DE JUSTIÇA TERAPÊUTICA}

O marco inicial da criminalização das drogas no Brasil se dá ainda nas 
Ordenações Filipinas, quando ainda se falava na posse ou comércio de "materiais venenosos".

Embora no Código do Império tenha deixado de contemplar a proibição do consumo ou comercialização de substâncias entorpecentes, no Código de 1890 veio a criminalização dos crimes contra a saúde pública, em que as "substâncias venenosas" encontravam espaço para serem proibidas (CARVALHO, 2007. p. 12).

$\mathrm{Na}$ Consolidação das Leis Penais do ano de 1932 também houve disciplina sobre a matéria, contudo, segundo Salo de Carvalho, foi a partir da década de 40 que surgiu uma política proibicionista de forma sistematizada (CARVALHO, 2007. p. 12). No ano de 1976 entrou em vigor a Lei n. 6.368, que tratava exclusivamente dos delitos relacionados às drogas, a qual veio substituída completamente no ano de 2006 pela edição da Lei n. 11.343, intitulada de "Nova Lei de Drogas", na qual se perceberam duas características importantes no que tange à política de drogas, quais sejam, o abrandamento da punição para o sujeito consumidor e a imposição de penas mais severas aos traficantes.

Um pouco antes, mais precisamente no ano de 1990, foi promulgado o Estatuto da Criança e do Adolescente - ECA, o qual prevê em seu artigo 112, conjugado com o artigo 101, a possibilidade de imposição de medida socioeducativa consistente em tratamento aos adolescentes, vislumbrando-se uma possibilidade de tratar os menores envolvidos com o consumo de drogas. Foi justamente esse o marco inicial do pensamento que culminou na criação do programa de Justiça Terapêutica no Brasil, um ano após o surgimento da primeira Corte de Drogas americana (FENSTERSEIFER, 2012. p. 23).

Atualmente, pode-se dizer que o Programa de Justiça Terapêutica, também denominado de Programa das Varas de Dependência Química (FENSTERSEIFER, 2012), é um mecanismo que busca afastar o acusado da esfera do processo penal, oferecendo um tratamento contra dependência química em vez de uma pena ou de um processo tradicional. Tal programa se destina àquelas pessoas que foram acusadas de praticarem crimes relacionados ao abuso de substâncias entorpecentes, crimes cometidos tanto pelo seu estado drogado quanto pela necessidade de sustentar seu próprio vício (FENSTERSEIFER, 2012).

Diferentemente das Cortes de Drogas americanas, entende-se que o oferecimento do programa brasileiro não deve ser condicionado ao assumir culpa pela conduta que está sendo imputada. Ademais, deve ser salientado que o programa não pode ser restringido ao delito de porte/posse de entorpecentes ${ }^{3} \mathrm{e}$

\footnotetext{
${ }^{3}$ A Justiça Terapêutica não pretende discutir a manutenção ou não do crime do art. 28 da Lei n. 11.343/06. A existência do programa não está condicionada à manutenção dessa figura típica, tendo como alvo principal delitos contra o patrimônio, lesões leves, entre outros delitos que tenham sido realizados em virtude da dependência química.
} 
o tratamento oferecido não pode resumir-se ao comparecimento em grupos de mútua-ajuda. Além disso, deve ser destacado que, ao contrário do que é priorizado nos programas de Cortes de Drogas americanas - como a redução da taxa de reincidência e dos gastos do Estado - o programa a ser adotado no Brasil deve objetivar oferecer uma alternativa mais benéfica para o indivíduo, que lhe traga algo de satisfatório, e apenas como consequência disso é que se deve observar a eventual redução da reincidência e dos gastos públicos.

Ao contrário do programa das Cortes de Drogas americanas, que já estão consolidadas nos Estados Unidos e em outros países, aqui no Brasil estão surgindo algumas experiências isoladas. Ainda não possuímos um modelo definitivo de Justiça Terapêutica. O modelo brasileiro busca, certamente, elementos do programa estadounidense, mas deve preocupar-se em não apenas reproduzir ideias, mas traduzi-las ao contexto no qual pretendemos aplicar, observando as peculiaridades da legislação e da cultura brasileira.

\section{CONSIDERAÇÕES FINAIS}

Inicialmente pode-se perceber que as Cortes de Drogas americanas são frutos de uma política criminal que vem sendo desenvolvida e constantemente modificada a diversas décadas. Depois do aumento da delinquência e, especialmente dos crimes relacionados às drogas, percebeu-se que o modelo antigo de resposta penal não era adequado a essa nova característica da criminalidade de massa.

Aspecto que deve ser destacado é o fato de que se trata, indubitavelmente, de uma política que elege alvos dentro da população, quais sejam, os sujeitos que cometem crimes por estarem drogados no momento da ação ou que viram no delito a possibilidade de sustentar seu vício.

Além disso, as Cortes de Drogas possuem um caráter correcionalista, buscando promover um tratamento com enfoque mais individualizado, reconhecendo as circunstâncias pessoais do participante, que visa a reduzir a criminalidade a partir da diminuição da reincidência, e isso de uma maneira mais barata para o Estado. Esse tratamento é disponibilizado para uma população previamente eleita, a partir do estabelecimento de critérios de elegibilidade, que pressupõe uma prognose mais favorável no que concerne ao afastamento do sujeito da criminalidade.

Outro ponto relevante é o fato de que para o indivíduo ingressar no programa, necessariamente, deve assumir a culpa pelo ato que lhe foi imputado, sendo o tratamento uma medida imposta como parole, algo que proporciona um aumento da rede de controle por parte do Estado.

É inquestionável concluir que o programa das Cortes de Drogas é im- 
perfeito, contudo, não podemos de antemão dispensá-lo completamente sem pensarmos em sua aplicação de modo que possa trazer mais benefícios do que prejuízos ao participante.

A partir dos estudos relacionados à criminologia cultural, pode-se perceber que, assim como os fatos se transformam em imagens que ao rodarem o mundo sofrem uma distorção quanto ao seu real significado, não podemos simplesmente acreditar que a criação de um programa de Justiça Terapêutica no Brasil seja a mera reprodução dos instrumentos utilizados nos Estados Unidos e nem que possui o mesmo significado (HEYWARD, 2010. pp. 01-16)

É justamente com esse sentimento que o programa de Justiça Terapêutica deve ser pensado, buscando afastar-se ao máximo das mazelas produzidas no modelo americano e adaptá-lo ao contexto nacional de forma que se possa buscar oferecer uma resposta alternativa à criminalidade associada à droga, que hoje se destaca também aqui no Brasil e pode ser refletida de forma diferente, no sentido de motivar o sujeito a tratar sua questão em relação às drogas de forma mais distanciada da esfera penal, priorizando-se o enfoque da saúde pública em vez do direito penal.

\section{REFERÊNCIAS}

CARVALHO, Salo de. A política criminal de drogas no Brasil: estudo criminológico e dogmático. 4. ed. Rio de Janeiro: Lumen Juris, 2007.

FENSTERSEIFER, Daniel Pulcherio. Varas de dependência química: um debate realizado a partir de observações da experiência canadense com DrugTreatmentCourts. Porto Alegre: Núria Fabris, 2012.

FOUCAULT, Michel. Vigiar e punir : história da violência nas prisões. 9. ed. Petrópolis: Vozes, 1991.

GARLAND, David. La cultura del control. Barcelona: Gedisa, 2005.

GHIRINGHELI, Rodrigo Azevedo. Visões da sociedade punitiva: elementos para uma sociologia do controle penal. In: GAUER, Ruth Maria Chittó (Coord.). Sistema penal e violência. Rio de Janeiro: Lumen Juris, 2006.

HERINGER JÚNIOR, Bruno. O sistema de justiça criminal dos Estados Unidos: um modelo em crise? Porto Alegre: Núria Fabris, 2013.

HEYWARD, Keith J. Opening the lens: Cultural criminology and the image. 
In: HEYWARD, Keith J.; PRESDEE, Mike. Framing the crime: cultural criminology and the image. Oxon, Routledge, 2010. p. 01-16.

LIMA, Flávio Augusto Fontes de. Justiça terapêutica: em busca de um novo paradigma. São Paulo: Scortecci, 2011. p. 63.

SIMON, Johnatan. Governing through crime: how the war on drugs transformed America democracy and created a culture of fear. New York: Oxford Press, 2009.

\title{
THE AMERICAN CRIME POLICY AND ITS ROLE IN THE CREATION OF DRUG COURTS: THE HISTORICAL INFLUENCES EXPERIENCED BY THE BRAZILIAN DRUG COURT PROGRAM
}

\begin{abstract}
This paper discusses the creation of the Drug Courts Program in Brazil from a historical approach, starting from the American drug crime policy and its development over the decades, as well as its influence on the Brazilian politics. This is a literature review for which two American authors were chosen as the main reference on the American crime policy as well as other related works that contribute to the theme in the discussion proposed by David Garland and Jonathan Simon, and which could explain the parallelism with the Brazilian context throughout time. It can be stated that the Brazilian drug crime policy has suffered, and continues suffering, a great influence of the American policies. It is envisaged that a number of measures taken in the United States were faithfully reproduced in Brazil, with some years in delay, causing similar effects, especially those that confirm a selective criminal system and reinforcing of social exclusion. Recently, however, an idea has risen, which seems to clash with these negative policies, seeking to minimize the effects of the application of criminal law while reinforcing the treatment that is considered as the main factor of several criminal behaviors, that is, the consumption of drugs. With the removal of the subject from the criminal consequences, being similar to treatment, the Drug Courts seek to reduce crime that until then was not being appropriately approached, considering the purposes proposed by criminal policies adopted over time. KEYWORDS: Drug crime policy; Drug courts; Crimes; Drugs.
\end{abstract}




\section{LA POLÍTICA CRIMINAL AMERICANA Y SU PAPEL EN LA CREACIÓN DE LOS TRIBUNALES DE DROGAS: INFLUENCIAS HISTÓRICAS SUFRIDAS POR EL PROGRAMA DE JUSTICIA TERAPÉUTICA}

RESUMEN: Esa investigación discute la creación del Programa de Justicia Terapéutica en Brasil a partir de un enfoque histórico, a partir de la política criminal de drogas americana y su desarrollo a lo largo de las décadas, así como su influencia sobre las políticas brasileñas. Se ha tratado de una pesquisa bibliográfica donde se ha elegido dos autores americanos como referencia principal acerca de la política criminal americana sobre drogas, así como otras obras relacionadas al tema que contribuyesen en la discusión del tema propuesto por David Garland y Jonathan Simon y que pudiesen explicar el paralelismo con el contexto brasileño al correr del tiempo. Es posible afirmar que la política criminal brasileña sobre drogas sufrió, y continúa sufriendo, gran influencia de las políticas americanas. Se vislumbra que inúmeras medidas tomadas en Estados Unidos han sido reproducidas fielmente en Brasil, con algunos años de retraso, causando consecuencias semejantes, especialmente aquellas que se muestran confirmadoras de un sistema criminal selectivo y de refuerzo de la exclusión social. Recientemente, entretanto, surge una idea que aparenta desacordar de esas políticas negativas y busca minimizar los efectos de la aplicación del derecho penal mientras refuerza el tratamiento de lo que es apuntado como principal factor de una gama de comportamientos criminosos, cual sea, el uso de drogas. Con alejamiento del sujeto de las consecuencias penales, aproximándolo de un tratamiento, los Tribunales de Drogas buscan reducir la criminalidad que hasta entonces no estaba siendo combatida de forma adecuada, considerando las finalidades propuestas por las políticas criminales adoptadas a lo largo del tiempo.

PALABRAS CLAVE: Política criminal de drogas; Tribunales de Drogas; Crímenes; Drogas. 